\title{
PENGARUH PROFESIONALISME AUDITOR INTERNAL TERHADAP \\ PENCEGAHAN DAN PENDETEKSIAN KECURANGAN (FRAUD)
}

(Survey pada BUMN yang Berkantor Pusat di Kota Bandung)

\author{
Mimin Widaningsih \\ Desy Nur Hakim \\ (Universitas Pendidikan Indonesia)
}

\begin{abstract}
ABSTRAK
Penelitian ini bertujuan untuk mengetahui pengaruh profesionalisme auditor internal terhadap pencegahan dan pendeteksian kecurangan (fraud) pada BUMN yang berkantor pusat di Kota Bandung. Metode penelitian yang digunakan dalam penelitian ini adalah metode deskriptif asosiatif. Data yang digunakan adalah data primer yang dikumpulkan melalui penyebaran kuesioner pada Sembilan BUMN yang Berkantor Pusat di Kota Bandung. Penelitian ini menggunakan pengujian statistik non - parametris yaitu dengan Spearman Rank dengan Software SPSS 20.0 for Windows.

Hasil penelitian menunjukkan bahwa besarnya pengaruh profesionalisme auditor internal terhadap pencegahan fraud adalah sebesar 40,07\%, dan sisanya sebesar 59,93\% dapat dipengaruhi oleh variabel lainnya yang tidak diteliti. Dan besarnya pengaruh profesionalisme auditor internal terhadap pendeteksian kecurangan adalah sebesar 37,33\%, sisanya sebesar 62,67\% dapat dipengaruhi oleh variabel lainnya yang tidak diteliti.
\end{abstract}

Kata kunci: Profesionalisme auditor internal, pencegahan kecurangan (fraud), pendeteksian kecurangan (fraud)

\section{PENDAHULUAN}

Badan Usaha Milik Negara (BUMN) merupakan salah satu pelaku kegiatan ekonomi yang penting di dalam perekonomian nasional, yang bersamasama dengan pelaku ekonomi lain yaitu swasta (besar-kecil, domestik-asing) dan koperasi, yang merupakan perwujudan dari bentuk bangun demokrasi ekonomi yang akan terus kita kembangkan secara bertahap dan berkelanjutan. Sebagai salah satu pelaku kegiatan ekonomi, keberadaan BUMN memiliki peran yang tidak kecil guna ikut mewujudkan kesejahteraan masyarakat sebagaimana diamanatkan oleh UUD 1945. (indonesia.go.id, 2010)

Dari penjelasan di atas sudah seharusnya BUMN memberikan pemasukan pada kas Negara atas laba yang diterimanya. Namun sayangnya, beberapa BUMN justru malah memberikan kerugian pada Negara. Pada tahun 2012 Menteri BUMN Dahlan Iskan menjelaskan mengenai Kerugian keenam belas BUMN yang diperkirakan hampir mencapai $\mathrm{Rp} 1,5$ triliun atau $\mathrm{Rp} 1.492 .499 .880 .000,00$. 
Adapun, sebanyak 125 BUMN lainnya mendapatkan laba. Hal ini dijelaskan pada Paparan Kinerja BUMN 2012. (sindonews.com, 28 Desember 2012).

Mirisnya di sisi lain kerugian - kerugian yang dialami oleh beberapa BUMN ini berasal dari penyimpangan keuangan. Penelaahan BAKN terhadap hasil pemeriksaan BPK semester I periode 2013 sedikitnya menemukan 510 kasus penyimpangan keuangan negara, antara lain sebanyak 234 kasus terkait kelemahan Sistem Pengendalian Internal (SPI), dan 276 kasus terkait ketidakpatuhan terhadap ketentuan perundangan-undangan. (hukumonline.com, 20 November 2013)

Menurut Fajri, Direktur Riset dan Pengembangan POLIGG (Policy and Law Institute for Good Governance) (2011) pada beberapa BUMN terlihat bahwa terjadi kerjasama sistemik melakukan rekayasa keuangan yang dilakukan karena lemahnya fungsi internal kontrol. Hal ini menunjukkan bahwa pihak-pihak yang melakukan internal kontrol mulai dari Dewan Komisaris sampai dengan Internal Audit tidak melakukan fungsinya dengan baik. (hrcentro.com, 2011)

Sedangkan Kepala BPKP, Mardiasmo, menyampaikan bahwa beberapa penyimpangan BUMN yang sering terjadi saat ini terkait akuntabilitas keuangan dapat dikurangi atau dicegah bila Auditor Internal berperan lebih efektif. Untuk itu, Auditor Internal agar selalu menjaga integritas dan secara berkesinambungan meningkatkan kompetensinya serta selalu siap berada di depan dan menjadi mitra yang profesional. (bpkp.go.id, 2011).

Profesionalisme merupakan suatu kredibilitas yang dimiliki auditor internal yang mana merupakan salah satu kunci kesuksesan dalam pengawasan perusahaan. Dengan adanya sikap profesionalisme dari auditor internal, diharapkan dapat diambil langkah untuk mendeteksi juga mengantisipasi setiap tindakan penyimpangan yang mungkin bisa terjadi. Saran dan sikap korektif dari auditor internal akan sangat membantu untuk mencegah kejadian penyimpangan terulang lagi dalam perusahaan dan menjadi baham penindakan bagi karyawan yang melakukan penyimpangan.

Sehingga dari fenomena-fenomena tersebut dapat kita lihat adanya suatu masalah pada penanganan kecurangan (fraud) yang menarik untuk diteliti. Penulis menduga terdapat suatu pengaruh positif dari profesionalisme auditor internal dalam pencegahan dan pendeteksian kecurangan, hal ini juga didukung oleh penelitian sebelumnya yang dilakukan oleh Eka Putri Pertiwi (2010) dengan judul "Analisis Pengaruh Komponen Keahlian Internal Auditor terhadap Pendeteksian dan Pencegahan Kecurangan (fraud) di Inspektorat Jendral Kementerian Perdagangan Republik Indonesia" Hasil penelitian ini menunjukkan bahwa ada pengaruh positif dari komponen keahlian internal auditor Inspektorat Jenderal Kementerian Perdagangan Republik Indonesia terhadap pendeteksian dan pencegaham kecurangan (fraud). Maka dari itu penulis tertarik untuk meneliti lebih lanjut dalam penelitian yang dilakukan terhadap 9 BUMN yang berpusat di Kota Bandung, mengingat BUMN yang berpusat di Kota Bandung dapat 
mewakili 7 dari 16 sektor usaha BUMN seperti industri pengolahan, logistik dan jasa, sarana angkutan dan pariwisata, telekomunikasi, perkebunan, industri strategis dan juga konstruksi.

\section{Rumusan Masalah}

Berdasarkan latar belakang yang telah dijelaskan sebelumnya, maka rumusan masalah dari penelitian ini adalah sebagai berikut; (1) Bagaimana Profesionalisme Auditor Internal pada BUMN yang berkantor pusat di Kota Bandung; (2) Bagaimana upaya pencegahan fraud pada BUMN yang berkantor pusat di Kota Bandung; (3) Bagaimana upaya pendeteksian fraud pada BUMN yang berkantor pusat di Kota Bandung; (4) Apakah ada pengaruh positif dari profesionalisme auditor internal terhadap pencegahan kecurangan (fraud) pada BUMN yang berkantor pusat di Kota Bandung; dan (5) Apakah ada pengaruh positif dari profesionalisme auditor internal terhadap pendeteksian kecurangan (fraud) pada BUMN yang berkantor pusat di Kota Bandung.

\section{KAJIAN PUSTAKA}

Setiap organisasi tentu saja mempunyai tujuannya sendiri, dimana pada dasarnya semua organisasi ingin memakmurkan organisasinya dan seluruh anggotanya. Seiring berkembangnya usaha atau bisnis suatu organisasi, maka pada saat itu pula bertambah keterbatasan organisasi untuk melakukan pengawasan atas aktivitas sehari-harinya.

Maka dari itu dibentuklah suatu pengendalian internal yang ditujukan untuk memastikan bahwa aktivitas perusahaan sudah berjalan efektif dan efisien. Menurut Arens (2008: hlm. 370) "Sistem pengendalian internal terdiri atas kebijakan dan prosedur yang dirancang untuk memberikan manajemen kepastian yang layak bahwa perusahaan telah mencapai tujuan dan sasarannya".

Namun meskipun sistem pengawasan ini sudah dirancang sedemikian rupa namun hingga saat ini masih banyak ditemukan kecurangan-kecurangan dalam organisasi, contohnya saja pada BUMN, beberapa media melansir bahwa kerugian yang dialami oleh BUMN rata - rata disebabkan oleh tindak kecurangan yang muncul akibat lemahnya pengendalian internal pada BUMN. Memang tidak dapat kita pungkiri bahwa tidak ada organisasi yang terbebas dari fraud, karena permasalahannya ada pada manusia, yang biasa kita dengar dengan "The man behind the gun". Baik atau buruknya suatu organisasi sangat tergantung pada sumber daya manusia di dalamnya. Dalam melaksanakan pengendalian atau pengawasan ini, organisasi atau perusahaan memberikan tugas dan kewenangan pada audit internal untuk memantau dan melakukan penilaian atas pengendalian internal sehingga tujuan perusahaan dapat terpenuhi. Menurut Hiro Tugiman (1997: hlm. 11) "Internal auditing atau pemeriksaan internal adalah suatu fungsi penilaian yang independen dalam suatu organisasi untuk menguji dan mengevaluasi kegiatan organisasi yang dilaksanakan”. 
Seorang auditor internal yang professional akan selalu berusaha untuk mencapai hasil terbaik dalam segala hal yang ia kerjakan. Maka auditor internal yang memiliki sikap profesionalisme akan melaksanakan tugasnya dalam pelaksanaan audit internal dengan baik. (Asikin, 2006). Sedangkan dari sisi lain, Amin Widjaja Tunggal (2012: hlm. 59) menjelaskan terdapat tiga unsur untuk mencegah dan mendeteksi fraud, yaitu; (1) Budaya jujur dan etika yang tinggi; (2) Tanggung jawab manajemen untuk mengevaluasi resiko fraud; (3) Pengawasan oleh komite audit.

Kecurangan (fraud) memang tidak cukup ditangani hanya dengan dilakukannya pencegahan, namun fraud juga harus dideteksi sedini mungkin. Maka dari itu kontribusi dari audit internal sangat dibutuhkan dalam hal ini. Kemampuan profesional merupakan tanggung jawab bagian audit internal dan setiap auditor internal. Dan pimpinan audit internal dalam setiap pemeriksaan haruslah menugaskan orang - orang yang secara bersama atau keseluruhan memiliki pengetahuan, kemampuan dan berbagai disiplin ilmu yang diperlukan untuk mrlaksanakan pemeriksaan secara tepat dan pantas.

Penelitian mengenai pengaruh profesionalisme auditor internal pernah dilakukan oleh Eka Putri Pertiwi (2010) dengan judul penelitian "Analisis Pengaruh Komponen Keahlian Internal Auditor terhadap Pendeteksian dan Pencegahan Kecurangan ( $f r a u d)$ di Inspektorat Jendral Kementerian Perdagangan Republik Indonesia" dimana poin - poin Profesionalisme auditor termasuk kedalamnya, penelitian ini menunjukkan bahwa komponen keahlian internal auditor berpengaruh positif terhadap pendeteksian dan pencegahan fraud pada Insp ektorat Jendral Kementrian Perdagangan Republik Indonesia

Berdasarkan pada latar belakang dan rumusan masalah yang telah dijelaskan sebelumnya maka penulis merumuskan hipotesis atas penelitian ini sebagai berikut : "Terdapat pengaruh positif dari profesionalisme auditor internal terhadap pencegahan dan pendeteksian kecurangan (fraud)" Metode Penelitian

Berdasarkan judul yang telah dikemukakan sebelumnya yaitu "Pengaruh Profesionalisme Auditor Internal terhadap Pencegahan dan Pendeteksian Kecurangan ( Fraud), maka terdapat tiga variabel yang akan diuji dalam penelitian ini, yaitu : (1) Profesionalisme Auditor Internal sebagai variabel independen (X); (2) Pencegahan Kecurangan sebagai variabel dependen pertama (Y1); (3) Pendeteksian Kecurangan sebagai variabel dependen kedua (Y2).

Berikut adalah tabel operasionalisasi variabel untuk penelitian ini. 
Tabel 1

Operasionalisasi Variabel Penelitian

\begin{tabular}{|c|c|c|c|c|}
\hline Variabel & Dimensi & Indikator & Skala & Instrumen \\
\hline $\begin{array}{l}\text { Variabel } \\
\text { bebas (X) } \\
\text { Profesionalis } \\
\text { me Auditor } \\
\text { Internal } \\
\text { Sumber : } \\
\text { International } \\
\text { Professional } \\
\text { Practices } \\
\text { Framework } \\
\text { (2012: hlm. } 3 \\
\text { - 8) }\end{array}$ & $\begin{array}{l}\text { 3. Tujuan, } \\
\text { kewenangan } \\
\text { dan } \\
\text { tanggung } \\
\text { jawab } \\
\\
\text { 4. Program } \\
\text { Quality } \\
\text { Assurance } \\
\text { dan } \\
\text { peningkatan } \\
\text { jaminan } \\
\text { fungsi audit } \\
\text { internal }\end{array}$ & $\begin{array}{l}\text { a. Independensi auditor } \\
\text { internal } \\
\text { b. Objektivitas auditor } \\
\text { internal } \\
\text { a. Pengetahuan, keahlian, } \\
\text { kompetensi lainnya } \\
\text { b. Mematuhi standar audit } \\
\text { c. Ketelitian profesional } \\
\text { d. Pendidikan berkelanjutan } \\
\text { a. Fungsi audit internal di } \\
\text { dalam organisasi } \\
\text { b. Kewenangan dalam } \\
\text { mengakses informasi } \\
\text { a. Penetapan } \\
\text { Assurance Quality } \\
\text { b. Peningkatan yang } \\
\text { berkelanjutan (Continous } \\
\text { Improvement) }\end{array}$ & Ordinal & $\begin{array}{c}\text { Kuesioner } \\
\text { No. } 1,2\end{array}$ \\
\hline $\begin{array}{l}\text { Variabel } \\
\text { terikat (Y1) } \\
\text { Pencegahan } \\
\text { Kecurangan } \\
(\text { Fraud }) \\
\text { Sumber : } \\
\text { Pusdiklatwas } \\
\text { BPKP } \\
(2008: 3)\end{array}$ & $\begin{array}{l}\text { 1. Penetapan } \\
\text { kebijakan } \\
\text { anti fraud }\end{array}$ & 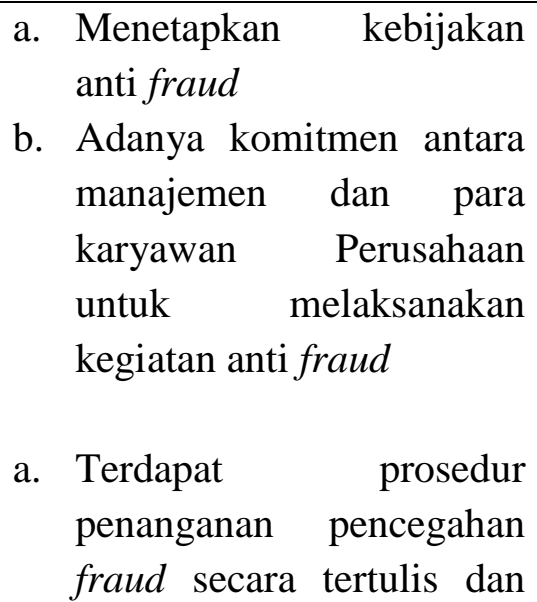 & Ordinal & 1,2 \\
\hline
\end{tabular}




\begin{tabular}{|c|c|c|}
\hline \begin{tabular}{|l} 
pencegahan \\
baku \\
2.1Pengendalian \\
intern \\
Perusahaan \\
2.2 Prosedur \\
mencegah \\
fraud secara \\
otomatis dalam \\
sistem \\
3. Organisasi \\
terhadap \\
fraud \\
5. Kepekaan \\
pegendalian \\
\end{tabular} & 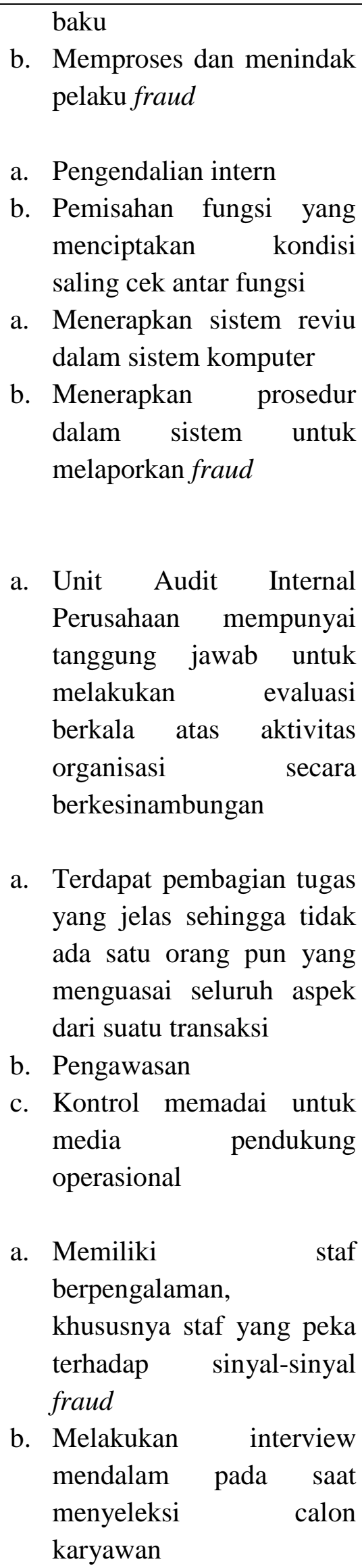 & 10,11 \\
\hline
\end{tabular}




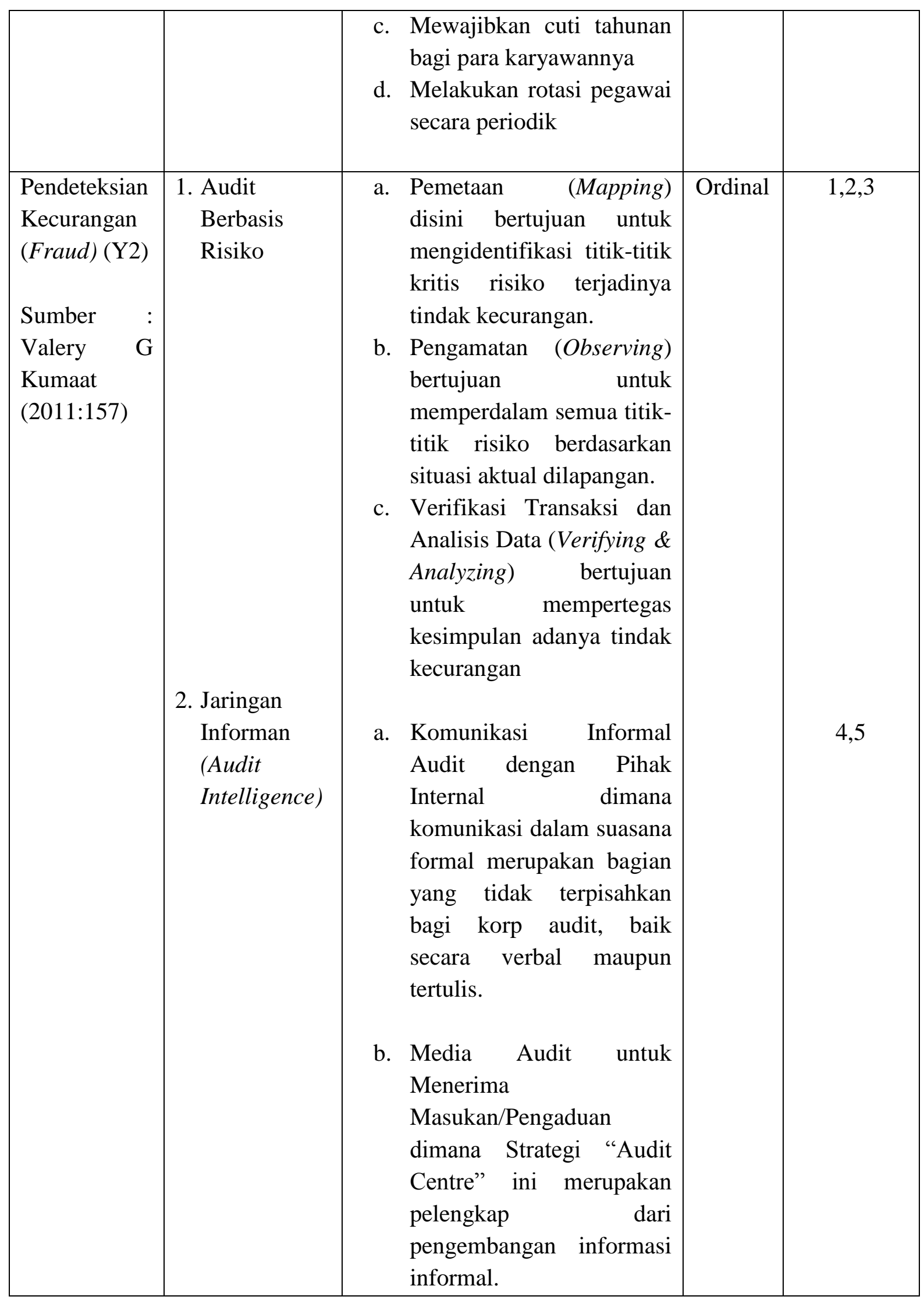

Terdapat 10 BUMN yang berkantor pusat di Kota Bandung. Namun hanya 9 BUMN yang dapat dijadikan populasi, karena PT KAI tidak berkenan untuk 
diteliti dikarenakan banyaknya permintaan pengisian kuesioner di waktu yang bersamaan. Berikut adalah nama - nama serta jumlah Staff Satuan Pengawasan Intern (SPI) BUMN yang berkantor pusat di Kota Bandung :

Tabel 2

Perusahaan BUMN yang berkantor pusat di Kota Bandung

\begin{tabular}{|c|c|c|c|}
\hline No. & Nama BUMN & Sektor & Jumlah Staff SPI \\
\hline 1 & PT Bio Farma & Aneka Industri & 13 \\
\hline 2 & PT Dirgantara Indonesia & Industri Strategis & 15 \\
\hline 3 & PT Indah Karya & Konstruksi & 6 \\
\hline 4 & PT Inti & Telekomunikasi & 10 \\
\hline 5 & PT Kereta Api Indonesia & Sarana Angkutan & - \\
\hline 6 & PT Len Industri & Telekomunikasi & 6 \\
\hline 7 & PT Perkebunan Nusantara VIII & Perkebunan & 15 \\
\hline 8 & PT Pindad & Industri Strategis & 8 \\
\hline 9 & PT Pos Indonesia & Logistik dan Jasa & 15 \\
\hline 10 & PT Telkom Tbk & Telekomunikasi & 50 \\
\hline \multicolumn{2}{|c|}{ Total } & 138 \\
\hline
\end{tabular}

\section{Sumber: data primer (diolah kembali)}

Adapun dalam penelitian ini digunakan Proportionate Stratified Random Sampling. Sampel yang diambil pada penelitian ini adalah Staff Satuan Pengawasan Intern (SPI) BUMN yang berpusat di Kota Bandung yang berjumlah 57. Angka ini didapatkan dari perhitungan dengan rumus slovin, yaitu sebagai berikut :

$$
\begin{gathered}
\mathrm{n}=\frac{N}{1+N e^{2}} \\
\mathrm{n}=\frac{138}{1+138(0.1)^{2}}=57
\end{gathered}
$$

Kererangan :

n : Besaran sampel

$\mathrm{N} \quad$ : Besaran populasi

E : Nilai kritis (batasan ketelitian) yang diinginkan (persen kelonggaran ketelitian penarikan sampel) yaitu $10 \%$

\section{HASIL DAN PEMBAHASAN}

Gambaran Profesionalisme Auditor Internal pada BUMN yang Berkantor Pusat di Kota Bandung

Secara keseluruhan rekapitulasi jawaban untuk variabel Profesionalisme Auditor Internal pada BUMN yang berkantor pusat di Kota Bandung adalah sebagai berikut : 
Tabel 3

Rekapitulasi Jawaban Variabel Profesionalisme Auditor Internal

\begin{tabular}{|c|c|c|c|c|c|}
\hline Variabel & Indikator & $\begin{array}{c}\text { Skor } \\
\text { Item }\end{array}$ & $\begin{array}{c}\text { Skor } \\
\text { Tertinggi }\end{array}$ & Persentase & Kategori \\
\hline \multirow{4}{*}{$\begin{array}{c}\text { Profesionalisme } \\
\text { Auditor } \\
\text { Internal }\end{array}$} & $\begin{array}{c}\text { Independensi dan } \\
\text { Objektivitas }\end{array}$ & 488 & 570 & $85.61 \%$ & $\begin{array}{c}\text { Sangat } \\
\text { Baik }\end{array}$ \\
\cline { 2 - 6 } & $\begin{array}{c}\text { Kemampuan dan } \\
\text { Keahlian Profesional }\end{array}$ & 950 & 1140 & $83.33 \%$ & Baik \\
\cline { 2 - 6 } dan Tangan, Wewenang & 521 & 570 & $91.40 \%$ & $\begin{array}{c}\text { Sangat } \\
\text { Baik }\end{array}$ \\
\cline { 2 - 6 } & $\begin{array}{c}\text { Program Quality } \\
\text { Assurance dan } \\
\text { Program } \\
\text { Pengembangan }\end{array}$ & 457 & 570 & $80.18 \%$ & Baik \\
\hline \\
\multirow{2}{*}{ Total } & $\mathbf{2 4 1 6}$ & $\mathbf{2 8 5 0}$ & $\mathbf{8 4 . 7 7 \%}$ & $\begin{array}{c}\text { Sangat } \\
\text { Baik }\end{array}$ \\
\hline
\end{tabular}

(Sumber: Data primer diolah)

Berdasarkan tabel diatas total skor yang diperoleh dari rekapitulasi jawaban untuk variabel Profesionalisme Auditor Internal adalah 2416.

Adapun untuk mendeskripsikan variabel X yaitu Profesionalisme Auditor Internal pada BUMN yang berkantor pusat di Kota Bandung dilakukan cara perbandingan dengan total skor tertinggi seperti berikut ini:

$$
\frac{2416}{2850} \times 100 \%=84.77 \%
$$

Maka angka $84.77 \%$ adalah termasuk pada kategori Sangat Baik. Sehingga dapat diketahui bahwa Profesionalisme Auditor Internal BUMN yang berpusat di Kota Bandung mempunyai profesionalisme yang Sangat Baik dengan memenuhi empat dimensi yaitu independensi dan objektivitas (independence and objectivity), keahlian dan kecermatan professional (proficiency and due professional care), tujuan, kewenangan, dan tanggung jawab (purpose, authority, and responsibility), dan yang terakhir program quality assurance dan peningkatan jaminan fungsi audit internal (quality assurance and improvement program).

Sedangkan secara keseluruhan rekapitulasi jawaban untuk variabel Pencegahan Kecurangan (Fraud) pada BUMN yang berkantor pusat di Kota Bandung adalah sebagai berikut : 
Tabel 4

Rekapitulasi Jawaban Variabel Pencegahan Kecurangan (Fraud) (Sumber: Data primer diolah)

\begin{tabular}{|c|c|c|c|c|c|}
\hline Variabel & Indikator & $\begin{array}{c}\text { Skor } \\
\text { Item }\end{array}$ & $\begin{array}{c}\text { Skor } \\
\text { Tertinggi }\end{array}$ & $\begin{array}{c}\text { Persent } \\
\text { ase }\end{array}$ & $\begin{array}{c}\text { Katego } \\
\text { ri }\end{array}$ \\
\hline \multirow{2}{*}{$\begin{array}{c}\text { Pencegahan } \\
\text { Kecurangan }\end{array}$} & $\begin{array}{c}\text { Penetapan Kebijakan } \\
\text { Anti Fraud }\end{array}$ & 481 & 570 & $84.39 \%$ & $\begin{array}{c}\text { Sangat } \\
\text { Baik }\end{array}$ \\
\cline { 2 - 6 } & $\begin{array}{c}\text { Prosedur Pencegahan } \\
\text { Baku }\end{array}$ & 1334 & 1710 & $78.01 \%$ & Baik \\
\cline { 2 - 6 } & Organisasi & 237 & 285 & $83.16 \%$ & Baik \\
\cline { 2 - 6 } & $\begin{array}{c}\text { Teknik Pengendalian } \\
\text { Kepekaan terhadap }\end{array}$ & 447 & 570 & $78.42 \%$ & Baik \\
\hline \multirow{2}{*}{ Total } & $\mathbf{2 9 2 6}$ & $\mathbf{3 7 0 5}$ & $\begin{array}{c}\mathbf{7 8 . 9 7} \\
\mathbf{\%}\end{array}$ & Baik \\
\hline
\end{tabular}

Berdasarkan tabel diatas total skor yang diperoleh dari rekapitulasi jawaban untuk variabel pencegahan kecurangan (fraud) adalah 2926.

Adapun untuk mendeskripsikan variabel Y1 yaitu pencegahan kecurangan (fraud) pada BUMN yang berkantor pusat di Kota Bandung dilakukan cara perbandingan dengan total skor tertinggi seperti berikut ini:

$$
\frac{2926}{3705} \times 100 \%=78.97 \%
$$

Maka angka $78.97 \%$ adalah termasuk pada kategori Baik. Sedangkan secara keseluruhan rekapitulasi jawaban untuk variabel Pendeteksian Kecurangan (Fraud) pada BUMN yang berkantor pusat di Kota Bandung adalah sebagai berikut :

Tabel 5

Rekapitulasi Jawaban Variabel Pendeteksian Kecurangan (Fraud)

\begin{tabular}{|c|c|c|c|c|c|}
\hline Variabel & Indikator & $\begin{array}{c}\text { Skor } \\
\text { Item }\end{array}$ & $\begin{array}{c}\text { Skor } \\
\text { Tertinggi }\end{array}$ & Persentase & Kategori \\
\hline \multirow{2}{*}{$\begin{array}{c}\text { Pendeteksian } \\
\text { Kecurangan }\end{array}$} & $\begin{array}{c}\text { Audit Berbasis } \\
\text { Risiko }\end{array}$ & 699 & 855 & $81.75 \%$ & Baik \\
\cline { 2 - 6 } & $\begin{array}{c}\text { Audit } \\
\text { Intelligence }\end{array}$ & 463 & 570 & $81.23 \%$ & Baik \\
\hline \multicolumn{2}{|r|}{ Total } & 1162 & 1425 & $81.54 \%$ & Baik \\
\hline
\end{tabular}

(Sumber: Data primer diolah) 
Berdasarkan tabel diatas total skor yang diperoleh dari rekapitulasi jawaban untuk variabel pendeteksian kecurangan (fraud) adalah 1162. Adapun untuk mendeskripsikan variabel Y2 yaitu pendeteksian kecurangan (fraud) pada BUMN yang berkantor pusat di Kota Bandung dilakukan cara perbandingan dengan total skor tertinggi seperti berikut ini:

$$
\frac{1162}{1425} \times 100 \%=81.54 \%
$$

Maka angka $81.54 \%$ adalah termasuk pada kategori Baik.

\section{Analisis Korelasi}

Pada penelitian ini analisis korelasi antara variabel $\mathrm{X}$ dan variabel $\mathrm{Y} 1$ serta variabel X dan variabel Y2 menggunakan analisis korelasi Spearman Rank dengan menggunakan Software SPSS 20.0 for Windows. Hal ini dilakukan untuk mengetahui pengaruh dan signifikansi variabel independen terhadap variabel dependen dengan menggunakan rata - rata perolehan skor dari setiap perusahaan. Adapun hasil perhitungannya akan ditampilkan dalam tabel dibawah ini :

Tabel 12

\section{Hasil Perhitungan Korelasi Spearman Rank} Correlations

\begin{tabular}{|rl|r|r|r|}
\hline & & \multicolumn{1}{|c|}{ X } & \multicolumn{1}{c|}{ Y1 } & \multicolumn{1}{c|}{ Y2 } \\
\hline & Correlation Coefficient & 1.000 & .633 & .611 \\
& Sig. (2-tailed) &. & .067 & .081 \\
& $\mathrm{~N}$ & 9 & 9 & 9 \\
& Correlation Coefficient & .633 & 1.000 & $.686^{*}$ \\
Spearman's rho $\mathrm{Y} 1$ & Sig. (2-tailed) & .067 &. & .041 \\
& $\mathrm{~N}$ & 9 & 9 & 9 \\
& Correlation Coefficient & .611 & $.686^{*}$ & 1.000 \\
& Y2 & .081 & .041 &. \\
& Sig. (2-tailed) & 9 & 9 & 9 \\
\hline
\end{tabular}

*. Correlation is significant at the 0.05 level (2-tailed).

Berdasarkan hasil perhitungan pada tabel 12, diperoleh nilai korelasi Spearman Rank sebesar 0.633 atau 63,3\% untuk hubungan profesionalisme auditor internal terhadap pencegahan kecurangan. Sedangkan untuk hubungan profesionalisme auditor internal terhadap pendeteksian kecurangan diperoleh nilai korelasi Spearman Rank sebesar 0.611 atau 61,6\%. Hubungan profesionalisme auditor internal terhadap pencegahan kecurangan memiliki nilai korelasi 0.633 , yang berada pada interval koefisien 0.60 - 0.799 atau tergolong memiliki hubungan positif yang kuat. Sedangkan untuk hubungan profesionalisme auditor internal dengan pendeteksian kecurangan yang mempunyai nilai koefisien korelasi 
0.611 , berada pada interval koefisien 0.60 - 0.799 atau tergolong memiliki hubungan positif yang kuat.

Dari kedua perhitungan diatas, dapat dimengerti pula bahwa nilai signifikansi dari pengujian yang pertama, yaitu $\mathrm{X}$ terhadap $\mathrm{Y} 1$ atau profesionalisme auditor internal terhadap pencegahan fraud adalah 0.067. Berdasarkan kriteria yang telah ditetapkan pada bab sebelumnya, yaitu jika signifikansinya kurang dari 0.10 maka $\mathrm{H}_{0}$ ditolak dan $\mathrm{H}_{\mathrm{a}}$ diterima, yang mana hal ini berarti bahwa terdapat hubungan yang signifikan antara profesionalisme auditor dengan pencegahan kecurangan (fraud) pada BUMN yang berkantor pusat di Kota Bandung. Sedangkan untuk perhitungan korelasi yang kedua yaitu hubungan profesionalisme auditor internal dengan pendeteksian kecurangan (fraud), dapat kita lihat bahwa hasil uji signifikansinya adalah 0,081 atau kurang dari 0,10 sehingga dapat disimpulkan bahwa $\mathrm{H}_{0}$ ditolak dan $\mathrm{H}_{\mathrm{a}}$ diterima, artinya terdapat hubungan yang signifikan antara profesionalisme auditor terhadap pendeteksian kecurangan (fraud) pada BUMN yang berkantor pusat di Kota Bandung.

Sedangkan untuk mengetahui besarnya pengaruh profesionalisme auditor internal terhadap pencegahan kecurangan (fraud) juga pengaruh profesionalisme auditor internal terhadap pendeteksian kecurangan (fraud) pada BUMN yang berkantor pusat di Kota Bandung, dilakukan uji koefisien determinasi dengan rumus sebagai berikut :

1. Pengaruh profesionalisme auditor internal tehadap pencegahan kecurangan

$$
\begin{aligned}
\mathrm{KD} & =\mathrm{r}^{2} \times 100 \% \\
& =(0.633)^{2} \times 100 \% \\
& =40.07 \%
\end{aligned}
$$

Koefisien determinasi dari hasil perhitungan didapat sebesar $40.07 \%$. Hal ini menunjukkan bahwa Profesionalisme Auditor Internal berpengaruh positif sebesar $40.07 \%$ terhadap Pencegahan Kecurangan pada BUMN yang berkantor pusat di Kota Bandung, sedangkan sisanya sebesar 59.93\% dapat dipengaruhi oleh variabel lainnya yang tidak diteliti.

2. Pengaruh profesionalisme auditor internal terhadap pendeteksian kecurangan

$$
\begin{aligned}
\mathrm{KD} & =r^{2} \times 100 \% \\
& =(0.611)^{2} \times 100 \% \\
& =37.33 \%
\end{aligned}
$$

Koefisien determinasi dari hasil perhitungan didapat sebesar 37.33\%. hal ini menunjukkan bahwa Profesionalisme Auditor Internal berpengaruh positif sebesar $37.33 \%$ terhadap Pendeteksian Kecurangan pada BUMN yang berkantor pusat di Kota Bandung, sedangkan sisanya sebesar 62.67\% dapat dipengaruhi oleh variabel lainnya yang tidak diteliti. 


\section{Pengaruh Profesionalisme Auditor Internal terhadap Pencegahan dan Pendeteksian Kecurangan (Fraud) (Survey pada BUMN yang Berkantor Pusat di Kota Bandung)}

Profesionalisme auditor internal merupakan kunci sukses dalam menjalankan suatu perusahaan, auditor internal yang memiliki sifat profesionalisme akan menjalankan tugas - tugasnya dengan baik. Termasuk pula tugasnya untuk membantu manajemen dalam mencegah dan mendeteksi kecurangan (fraud) yang terjadi di lingkungan perusahaan. Berdasarkan perhitungan analisis korelasi dengan bantuan Software SPSS 20.00 for Windows terhadap kuesioner yang disebar kepada sembilan BUMN yang berkantor pusat di Kota Bandung, dapat disimpulkan bahwa Profesionalisme Auditor Internal berhubungan positif dan signifikan dengan pencegahan kecurangan, begitu pula hubungannya dengan pendeteksian kecurangan. Sedangkan besarnya pengaruh positif dari profesionalisme auditor internal terhadap pencegahan kecurangan adalah sebesar $40.07 \%$, dan sisanya sebesar 59.93\% dapat dipengaruhi oleh variabel lainnya yang tidak diteliti seperti perekrutan staf secara seksama, integritas budaya dan pencegahan kerugian dalam organisasi serta pengauditan secara teratur terhadap transaksi - transaksi oleh audit internal. Kemudian besarnya pengaruh positif dari profesionalisme auditor internal terhadap pendeteksian kecurangan adalah sebesar $37.33 \%$, sisanya sebesar $62.67 \%$ dapat dipengaruhi oleh variabel lainnya yang tidak diteliti seperti budaya jujur, etika yang tinggi, tanggung jawab manajemen untuk mengevaluasi risiko serta faktor lain yang ada di pihak pelaku.

\section{SIMPULAN}

\section{Simpulan}

Berdasarkan hasil penelitian dan pembahasan mengenai pengaruh profesionalisme auditor internal terhadap pencegahan dan pendeteksian kecurangan ( fraud) yang dilakukan pada sembilan BUMN yang berkantor pusat di Kota Bandung, maka dapat disimpulkan bahwa :

1. BUMN yang berkantor pusat di Kota Bandung memiliki profesionalisme auditor internal yang sangat baik. Hal ini dapat kita lihat berdasarkan pada hasil olah kuesioner dengan dimensi independensi dan objektivitas (independence and objectivity), keahlian dan kecermatan professional (proficiency and due professional care), tujuan, kewenangan, dan tanggung jawab (purpose, authority, and responsibility), dan yang terakhir program quality assurance dan peningkatan jaminan fungsi audit internal (quality assurance and improvement program).

2. Upaya pencegahan kecurangan (fraud) pada BUMN yang berkantor pusat di Kota Bandung tergolong pada kategori Baik. Hal ini berdasarkan pada hasil olah kuesioner yang merujuk pada dimensi - dimensi seperti 
Penetapan Kebijakan Anti fraud, Prosedur Pencegahan Baku, Organisasi, Teknik Pengendalian dan Kepekaan terhadap Fraud.

3. Upaya pendeteksian kecurangan (fraud) pada BUMN yang berkantor pusat di Kota Bandung tergolong pada kategori Baik. Hal ini sesuai dengan hasil olah kuesioner yang berdasarkan pada dimensi Audit Berbasis Risiko dan Jaringan Informan (Audit Intelligence).

4. Terdapat pengaruh positif yang signifikan dari profesionalisme auditor internal terhadap pencegahan kecurangan pada BUMN yang berkantor pusat di Kota Bandung yaitu sebesar $40.07 \%$

5. Terdapat pengaruh positif yang signifikan dari profesionalisme auditor internal terhadap pendeteksian kecurangan pada BUMN yang berkantor pusat di Kota Bandung yaitu sebesar 37.33\%

\section{Saran}

Berdasarkan pada hasil penelitian yang telah dilakukan dengan judul pengaruh Profesionalisme Auditor Internal terhadap Pencegahan dan Pendeteksian Kecurangan (Fraud) (Survey pada BUMN yang Berkantor Pusat di Kota Bandung), penulis mengajukan beberapa saran guna untuk meningkatkan pencegahan dan pendeteksian kecurangan serta menambah kesempurnaan penelitian selanjutnya :

1. Untuk BUMN yang berkantor pusat di Kota Bandung :

a. Dimensi Program Quality Assurance dan peningkatan jaminan fungsi audit internal dari variabel Profesionalisme Auditor Internal memiliki persentase terrendah. Karena itu, Satuan Pengawasan Intern (SPI) pada BUMN yang berkantor pusat di Kota Bandung disarankan untuk meningkatkan penyampaian perbaikan kinerja pada manajemen, hal ini penting untuk memastikan bahwa kegiatan audit internal sudah sesuai dengan aturan serta efisien.

b. Dimensi Kepekaan terhadap Fraud dari variabel pencegahan kecurangan memiliki persentase terrendah. Penulis menyarankan agar BUMN yang berkantor pusat di Kota Bandung meningkatkan "SILA" atau sikap Suspicious, Inquistive, Logical and Analytical Mind, sehingga Staff Satuan Pengawasan Intern akan lebih peka terhadap sinyal - sinyal fraud.

c. Dimensi Pengembangan Jaringan Informan (Audit Intelligence) dari variabel pendeteksian kecurangan memiliki persentase terrendah. Oleh karena itu, penulis menyarankan agar Satuan Pengawasan Intern pada BUMN yang berkantor pusat di Kota Bandung meningkatkan komunikasi informal dengan pihak internal guna mendapatkan informasi yang lebih luas dan juga mengoptimalkan media audit secara berkesinambungan. 
2. Peneliti Selanjutnya

a. Menambahkan variabel independen lain seperti kompetensi atau independensi auditor internal.

b. Menambah sampel penelitian, pada penelitian ini sampel hanya terbatas pada BUMN yang berkantor pusat di Kota Bandung, guna meningkatkan kualitas hasil penelitian, penulis menyarankan untuk dilakukan penelitian pada BUMN se-Jawa Barat atau seIndonesia.

\section{DAFTAR PUSTAKA}

Airin N. A \& Armanto W. (2014). Pengaruh Audit Internal terhadap Pendeteksian dan Pencegahan Fraud (Kecurangan Akuntansi) (Suatu Studi pada PT KTM). Jakarta: Universitas Binus

Amrizal. (2004). Pencegahan dan Pendeteksian Kecurangan oleh Auditor. Jakarta Arens, Alvin A. (2008). Auditing dan Jasa Assurance. Edisi Keduabelas. Jakarta: Erlangga

Bachtiar, Asikin. (2006). Pengaruh Sikap Profesionalisme Internal Auditor

Terhadap Peranan Internal Auditor Dalam Pengungkapan Temuan Audit. Jurnal Bisnis, Manajemen dan ekonomi, volume 7 nomor 3 Februari 2006.

ASH. (2013). Tidak Semua Kerugian BUMN Jadi Kerugian Negara. [Online].

Diakses dari

http://www.hukumonline.com/berita/baca/lt522708e1d18de/tidak-semua kerugian-bumn-jadi-kerugian-negara

Badan Pengawasan Keuangan Dan Pembangunan. (2008). Fraud Auditing. Edisi kelima. Bogor: Pusdiklatwas BPKP.

Badan Pengawasan Keuangan dan Pembangunan. (2011). Audit Internal Harus

Siap Untuk Selalu Berada di Depan Menjadi Mitra yang Profesional.

[Online]. diakses dari :

http://www.bpkp.go.id/dan/berita/read/7275/30/auditor-internal-harussiap-untuk-selalu-berada-di-depan-dan-menjadi-mitra-yangprofesional.bpkp

Badan Pemeriksa Keuangan. (2012). Warta BPK Edisi Kaleidoskop 2012. Jakarta: Badan Pemeriksa Keuangan

Badan Pemeriksa Keuangan. (2013). BPK Audit Subsidi BUMN. [Online]. Diakses dari : http://www.bpk.go.id/news/bpk-audit-subsidi-bumn

Evi, H. (2013). Pengaruh Profesionalisme Auditor Intenal terhadap Pendeteksian Fraud Assets Missappropriation. (Skripsi). Universitas Pendidikan Indonesia, Bandung

Fajri, Mohamad. (2011). Kasus Waskita dan Kelemahan Implementasi GCG di indonesia. [Online] diakses dari :

http://www.hrcentro.com/artikel/kasus_waskita_dan_kelemahan_impleme ntasi_gcg_indonesia_090927.html 
Hartadi, Bambang. (1999). Sistem Pengendalian Intern: Dalam Hubungannya dengan Manajemen dan Audit. Yogyakarta : BPFE

Hery. 2010. Potret Audit Internal. Bandung: Alfabeta.

H. S. Hadibroto dan Oemar Witarsa. (1985). Sistem Pengawasan Intern. Jakarta:

LPFE. Universitas Indonesia

Husaini. (2009). Komite Audit \& Audit Internal: Integritas Pengawasan

Korporasi. Bandung: UNPAD Press

Ikatan Akuntan Publik. (2001). Standar Profesi Akuntan Publik. Jakarta: Salemba Empat

IIA. (2012). International Professional Practices Framework. The Institute of Internal Auditor Inc. USA

Kementrian Sekretariat Negara Republik Indonesia. (2010). BUMN. [Online].

Diakses dari http://www.indonesia.go.id/in/bumn

Kumaat, Valery G. (2011). Internal Audit. Jakarta: Erlangga.

Mulyadi. (2009). Auditing. Jakarta: Salemba Empat

Michael Agustinus. (2012). 2012, 16 BUMN catat kerugian Rp 1,5 T. [Online].

Diakses dari http://ekbis.sindonews.com/read/701543/34/2012-16-bumncatat-kerugian-rp1-5-t-1356680359

Misbahol Munir. (2012). Pengendalian Intern Buruk Penyebab BUMN Korup.

[Online]. Diakses dari

http://ekbis.sindonews.com/read/658966/33/pengendalian-intern-buruk-

penyebab bumn-korup-1342420267

Pertiwi, Eka Putri. (2010). Analisis Pengaruh Komponen Keahlian Internal

Auditor terhadap Pendeteksian dan Pencegahan Kecurangan (fraud) di

Inspektorat Jenderal Kementerian Perdagangan Republik Indonesia.

(Skripsi). Universitas Syarif Hidayatullah, Jakarta

Rading et al. (2007). Internal Auditing: Assurance \& Consulting Services. The

IIA Research Foundation

Ratna, A. (2013). Pengaruh Audit Internal terhadap Pencegahan dan

Pendeteksian Fraud (Kecurangan) (Suatu Studi pada Gabungan Koperasi

Pegawai Republik Indonesia (GPKRI) Jawa Barat). (Skripsi). Universitas

Pasundan, Bandung.

Sawyer, Lawrence. (2009). Audit Internal. Jakarta: Salemba Empat

Sugiyono. 2002. Metode Penelitian Bisnis. Bandung: Alfabeta (2009). Metode Penelitian Bisnis. Bandung: Alfabeta (2010). Metode penelitian Kuantitatif Kualitatif dan R\&D. Bandung:

Alfabeta

(2012). Metode Penelitian Bisnis. Cetakan keenam belas. Bandung:

Alfabeta.

(2012). Statistika untuk Penelitian. Cetakan kedua puluh. Bandung:

Alfabeta.

(2013). Statistik Nonparametris. Bandung: Alfabeta 
Sukirno. (2014). Laba 20 Emiten BUMN Merosot Jadi Rp 37,21 Triliun. [Online]. Diakses dari http://market.bisnis.com/read/20140826/192/252459/laba-20emiten-bumn-merosot-jadi-rp3721-triliun

Soerjono, Soekanto. (1990). Sosiologi Suatu Pengantar. Jakarta: PT Rajawali

Synthia, D. (2014). Pengaruh Peran Auditor Internal terhadap Efektivitas Pengendalian Internal pada Bank Perkreditan Syariah di Jawa Barat. (Skripsi). Universitas Pendidikan Indonesia, Bandung Tunggal, Amin Widjaja. (2012) The fraud Audit Mencegah dan Mendeteksi Kecurangan Akuntansi. Jakarta: Harvarindo

Tugiman, Hiro. (1997). Standar Profesional Audit Internal. Yogyakarta: Kanisius Tugiman, Hiro. (2003). Standar Profesional Audit Internal. Yogyakarta: Kanisius Tugiman, Hiro. (2006). Standar Profesional Audit Internal. Yogyakarta: Kanisius Umar, Husen. (2008). Metode Riset Bisnis. Jakarta: PT Gramedia Pustaka 